\title{
Influence of in situ progressive N-terminal is still controversial truncation of glycogen branching enzyme in Escherichia coli DH5a on glycogen structure, accumulation, and bacterial viability
}

Liang Wang ${ }^{1}$, Ahmed Regina², Vito M Butardo $\mathrm{Jr}^{3}$, Behjat Kosar-Hashemi², Oscar Larroque ${ }^{2}$, Charlene M Kahler ${ }^{1}$ and Michael J Wise ${ }^{4^{*}}$

\begin{abstract}
Background: Glycogen average chain length $(\mathrm{ACL})$ has been linked with bacterial durability, but this was on the basis of observations across different species. We therefore wished to investigate the relationship between bacterial durability and glycogen ACL by varying glycogen average chain length in a single species. It has been shown that progressive shortening of the $\mathrm{N}$-terminus of glycogen branching enzyme (GBE) leads to a lengthening of oligosaccharide inter-a-1,6-glycosidic chain lengths, so we sought to harness this to create a set of Escherichia coli DH5a strains with a range of glycogen average chain lengths, and assess these strains for durability related attributes, such as starvation, cold and desiccation stress resistance, and biofilm formation.

Results: A series of Escherichia coli DH5a mutants were created with glgB genes that were in situ progressively N-terminus truncated. N-terminal truncation shifted the distribution of glycogen chain lengths from 5-11 DP toward 13-50 DP, but the relationship between glgB length and glycogen $A C L$ was not linear. Surprisingly, removal of the first 270 nucleotides of glgB (glgB $\triangle 270$ ) resulted in comparatively high glycogen accumulation, with the glycogen having short ACL. Complete knockout of glgB led to the formation of amylose-like glycogen containing long, linear a1,4-glucan chains with significantly reduced branching frequency. Physiologically, the set of mutant strains had reduced bacterial starvation resistance, while minimally increasing bacterial desiccation resistance. Finally, although there were no obvious changes in cold stress resistance or biofilm forming ability, one strain ( $g$ lgB $\Delta 180$ ) had significantly increased biofilm formation in favourable media.

Conclusions: Despite $g / g B$ being the first gene of an operon, it is clear that in situ mutation is a viable means to create more biologically relevant mutant strains. Secondly, there was the suggestion in the data that impairments of starvation, cold and desiccation resistance were worse for the strain lacking $g \operatorname{lgB}$, though the first of these was not statistically significant. The results provide prima facie evidence linking abiotic stress tolerance with shorter glycogen ACL. However, further work needs to be done, perhaps in a less labile species. Further work is also required to tease out the complex relationship between glycogen abundance and glycogen structure.
\end{abstract}

Keywords: Glycogen structure, Microbial abiotic stress tolerance

\footnotetext{
* Correspondence: Michael.Wise@uwa.edu.au

${ }^{4}$ School of Chemistry and Biochemistry, University of Western Australia, Perth, Australia

Full list of author information is available at the end of the article
}

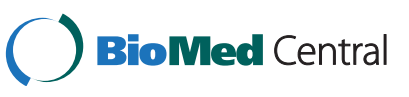

(c) 2015 Wang et al.; licensee BioMed Central. This is an Open Access article distributed under the terms of the Creative Commons Attribution License (http://creativecommons.org/licenses/by/4.0), which permits unrestricted use, distribution, and reproduction in any medium, provided the original work is properly credited. The Creative Commons Public Domain Dedication waiver (http://creativecommons.org/publicdomain/zero/1.0/) applies to the data made available in this article, unless otherwise stated. 


\section{Background}

Glycogen is a major intracellular carbon and energy reserve in microorganisms, which is normally accumulated when a carbon source is abundant while other nutrients are deficient [1]. It is a hyperbranched homopolysaccharide consisting of only glucosyl residues, which were linked together by $\alpha-1,4$-glycosidic bonds in linear chains and $\alpha$-1,6-glycosidic bonds at branching points [1]. Currently, there are more than 50 bacterial species reported to store glycogen [2] and 245 bacterial species harboring the essential genes for glycogen metabolism [3]. The order of these genes in the common $g l g$ operon is not always consistent [4] and the precise role for glycogen in bacteria is still not clearly understood [5]. Previous studies have linked glycogen with bacterial starvation survival [6], environmental persistence and transmission [5], and symbiotic performance [7], though its role in bacterial colonization and virulence is still controversial [8-10]. In addition, Pan et al. [11] reported that trehalose synthase (TreS) converts glycogen to trehalose. Chandra et al. [12] also identified a widespread non-classical GlgE pathway, converting trehalose to $\alpha$-glucan (glycogen). A connection between glycogen and trehalose may extend the function of glycogen to bacterial cold and desiccation resistance due to the protective role of trehalose under these stresses $[13,14]$.

Although the role of glycogen in bacteria is still under investigation, according to a recent review, glycogen structure, specifically average chain length $(\mathrm{ACL})$ - the average number of 1,4-glycosidic-bonded glucosyl units between 1,6-glycosidic- bonded glucosyl units - may play an important role in bacterial durability [3]. However, only a few biological studies and theoretical analyses are currently available to support this proposal [3]. In order to test this hypothesis experimentally, a set of bacterial strains from the same species accumulating glycogen with different ACLs was developed and their performance under a variety of conditions was compared. Five enzymes are considered to be core members of the glycogen metabolic pathway: glycogen synthase (GlgA, EC 2.4.1.21), ADP-glucose pyrophosphorylase ( $\mathrm{GlgC}, \mathrm{EC}=2.7 .7 .27$ ), glycogen branching enzyme (GBE) (GlgB, EC 2.4.1.18), glycogen phosphorylase (GlgP, EC 2.4.1.1), and glycogen debranching enzyme (GlgX, EC 3.2.1.-) [3,15]. A number of these genes influence bacterial inter- $\alpha$-1,6-glycosidic chain-length distribution patterns: GlgB, GlgP and GlgX $[16,17]$, and could therefore be starting points toward our aim of varying chain length distributions in a single species. It is known that $E$. coli GlgP can only act on linear chains longer than 4 glucosyl residues from the non-reducing end [16], while GlgX cleaves short oligosaccharides (up to 4 glucosyl residues) from $\alpha-1,6-$ branching points [17]. Accordingly, glgP-deficient cells accumulate glycogen with longer chain lengths while $g l g X$-deficient cells have more glycogen with shortbranched chains [16,17]. However, both $\operatorname{glg} P$ and $\operatorname{glg} X$ are involved in the glycogen degradation pathway and mutations would make bacterial cells unable to properly utilize glycogen. For example, $g l g X$-deficient Vibrio cholera is observed to die faster under nutrient-limited conditions although more glycogen is accumulated than in the wild type strain [5]. In addition, over-accumulation of glycogen has protective roles against stresses such as low $\mathrm{pH}$ and osmotic stresses [5]. Of the other proteins involved in glycogen synthesis/metabolism, inactivation of GlgA leads to the loss of glycogen production $[9,18]$, although a recent study indicated that there is an accessory pathway in $E$. coli that can utilize maltodextrin to synthesize glycogen in the absence of GlgA [19]. In addition, GlgC has a ratecontrolling role by providing ADP-glucose for glycogen synthesis [15]. Thus, both GlgA and GlgC are not suitable for manipulating glycogen structure, leaving $\mathrm{GlgB}$ as the prime candidate for modification.

GBE belongs to GH13 family [20] and is involved in two processes: hydrolyzing $\alpha-1,4$-glycosidic linkages and transferring oligosaccharide chains of mainly $5-16$ glucosyl residues to a neighboring $\alpha-1,6$-position [21]. Modification of the N-terminus of bacterial GBE can provide a practical approach to altering bacterial glycogen ACL quantitatively; an earlier study showed that proteolysis of the first 112 amino acids (AA) of Escherichia coli GBE changes glycogen chain length distribution patterns [22]. Later, Devillers et al. [23] reported that the length of the N-terminus of GBE is positively correlated with the length of the transferred chains. A recent experimental study also revealed that GBE $\mathrm{N}$-terminus is responsible for substrate specificity and glycogen branching pattern by swapping N-terminal domains between Deinococcus geothermalis and Deinococcus radiodurans [20].

To date, all studies $[20,23,24]$ involving the GBE Nterminus have been performed using purified protein and amylose as an artificial substrate, which may not reflect the real situation inside bacteria. To test the function of the N-terminus of GBE, a set of E. coli DH5 $\alpha$ mutants with in situ progressive truncation of $\mathrm{N}$-terminus of GBE were constructed. The influence of changing the length of the $\mathrm{N}$-terminus of GBE on glycogen structure and accumulation was assessed. The effect of any changes in glycogen expression on bacterial growth under abiotic stresses, such as starvation, cold and desiccation, were assessed. Biofilm formation was also measured, considering its relationship with polysaccharide formation and bacterial persistence $[8,25,26]$. To the best of our knowledge, this is the first study of in situ N-terminal truncation of GlgB and its influences on glycogen structure, accumulation, and bacterial durability. 


\section{Methods}

Bacterial strains, plasmids, and growth conditions E. coli strains used in this study were as follows $\mathrm{DH} 5 \alpha, \mathrm{DH} 5 \alpha$ glgB $\Delta 90, \mathrm{DH} 5 \alpha$ glgB $\Delta 180, \mathrm{DH} 5 \alpha \operatorname{glgB} \Delta 270$, DH5 $\alpha$ glgB $\Delta 369$, DH5 $\alpha \Delta$ glgB, BL21(DE3), JM109, DB3.1, and Top10 (Additional file 1: Table S1). All bacteria were cultured on agar containing $1 \times \mathrm{M} 9$ salts (Sigma) supplemented with $1.5 \%$ agarose, $0.4 \%$ glucose, $0.2 \%$ thiamine, $2 \mathrm{mM} \mathrm{MgSO} 4$, and $0.1 \mathrm{mM} \mathrm{CaCl} 2$ for iodine vapor staining. Luria-Bertani agar plates contained antibiotics at the following concentrations: $100 \mu \mathrm{g} / \mathrm{ml}$ ampicillin, $50 \mu \mathrm{g} / \mathrm{ml}$ of kanamycin, or $25 \mu \mathrm{g} / \mathrm{ml}$ chloramphenicol. Unless otherwise stated, bacteria were cultured at $37^{\circ} \mathrm{C}$ incubator and shaken at $200 \mathrm{rpm}$ in a rotary shaking incubator.

\section{Construction of in situ glgB mutated strains}

Five mutants of $E$. coli $\mathrm{DH} 5 \alpha$ expressing progressively deleted GBE in the chromosomal position of $\operatorname{glg} B$ were constructed (Figure 1A). E. coli DH5 $\alpha$ glgB $\Delta 90$ (4-90 nucleotides deleted), E. coli $\mathrm{DH} 5 \alpha$ glgB $\Delta 180$ (4-180 nucleotides deleted), E. coli $\mathrm{DH} 5 \alpha$ glgB $\Delta 270$ (4-270 nucleotides deleted), $E$. coli DH5 $\alpha$ glgB $\Delta 369$ (4-369 nucleotides deleted), E. coli $\mathrm{DH} 5 \alpha \Delta$ glgB (4-2186 nucleotides deleted). $\lambda$-Red recombination system (Plasmids pKD4, pKD46, and pCP20) by Datsenko and Wanner [27] was generously provided by Dr. Harry Sakellaris. Plasmid pKD46 was first transformed into $E$. coli $\mathrm{DH} 5 \alpha$. Then, five pairs of primers with 36 nucleotides in $5^{\prime}$ and $3^{\prime}$ regions that correspond to homologous regions in $\operatorname{glg} B$ were used to amplify linear PCR products from plasmid pKD4. The list of primers can be found in Additional file 1: Table S2A, and the combinations of primers used for the particular deletion mutants can be found as Additional file 1: Table S2B. All the five linear PCR products had the length of $1.5 \mathrm{~kb}$ and contain a kanamycin resistance gene flanked by FRT sites. These linear PCR products were electroporated into competent E. coli DH5 $\alpha$ cells carrying pKD46. Recombination catalyzed between the FRT sites and the $\operatorname{glg} B$ locus by the lambda red recombinase resulted in the replacement of the wild type $g \lg B$ chromosomal locus with the deleted variants (Figure 1A).

Successful homologous recombination into the $\operatorname{glg} B$ locus with linear PCR products was verified by the existence of the kanamycin resistance gene in the chromosome. Primers $\mathrm{K}_{\mathrm{t}}$ and $\mathrm{K}_{2}$ (Additional file 1: Table S2A) were used for verification [27]. A helper plasmid pCP20 encoding FRT recombinase was introduced into recombined strains, to facilitate the removal of the kanamycin resistance cassette by crossover of FRT sites. To confirm the loss of the kanamycin resistance cassette, flanking primers, $\mathrm{FP} g \lg B$ and $\mathrm{RP} \lg B$ (Additional file 1: Table

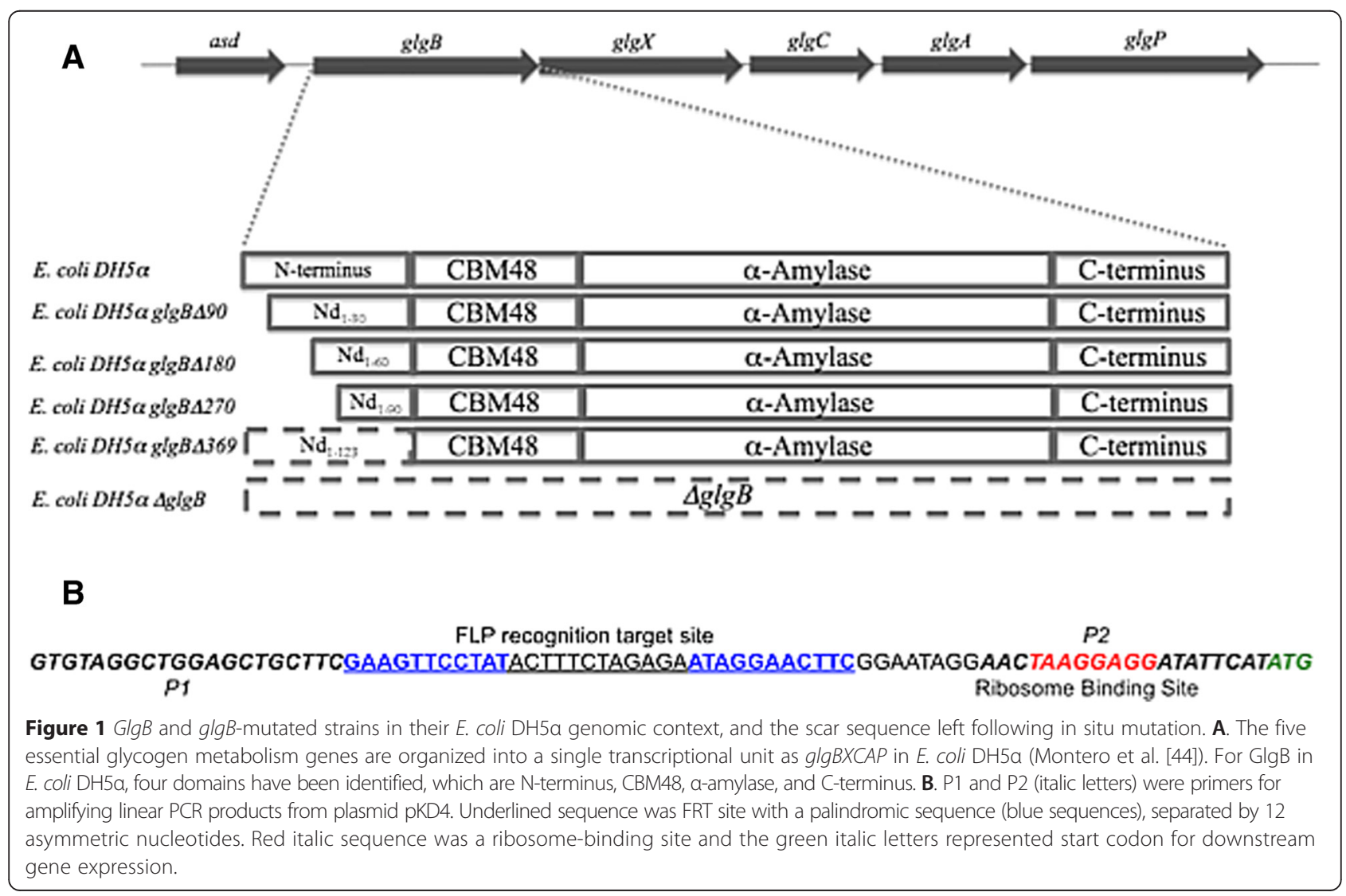


$\mathrm{S} 2 \mathrm{~A}$ ), which covered the full $\operatorname{glgB}$ region, was used to verify the variation in the length of the locus. Finally, in order to make sure that no point mutations existed in the constructed mutants, PCR-based gene sequencing was done for the $g l g B$-truncated region. Finally, plasmid pCP20 was removed from each of the recombinant strains by culturing at $37^{\circ} \mathrm{C}$. Antibiotics sensitivity test was then performed on LB agar plate (100 $\mu \mathrm{g} / \mathrm{ml}$ ampicillin) to confirm the loss of the plasmid.

\section{Quantitative reverse transcriptase real time PCR (qRT-PCR)}

Expression levels of $g \lg B, g \lg X, g \lg C, g \lg A, g \lg P$ were examined by qRT-PCR. Total RNA from stationary phase cells (20 hour) was extracted using the RiboPure ${ }^{\mathrm{T}}$ Bacteria Kit (Invitrogen). Extracted RNA was then digested by DNaseI to reduce the risk of genomic DNA contamination. iScript ${ }^{\mathrm{TM}}$ cDNA synthesis kit (Bio-Rad) was used to synthesize cDNA, following manufacturer's instructions. Quantitative real-time PCR was set up (total of $20 \mu \mathrm{L}$ reaction) by mixing RNA template, $2 \times$ SensiFAST $^{\mathrm{TM}}$ SYBR\&Fluorescein one-step mix, $10 \mu \mathrm{M}$ forward primer, and $10 \mu \mathrm{M}$ reverse primer. The PCR was performed in a Rotor-Gene 3000 PCR machine (Corbett Research) for 40 cycles with 2-step cycling, which consisted of denaturation at $95^{\circ} \mathrm{C}$ for $5 \mathrm{~s}$ and annealing at $60^{\circ} \mathrm{C}$ for $20 \mathrm{~s}$, with a final extension at $72^{\circ} \mathrm{C}$ for 1 minute. Melt curve analysis confirmed the presence of a single product from each PCR reaction (data not shown). The primer pairs used to assess the transcript levels were as follows: $g \lg B$ was amplified using glgBF and glgBR; $g \lg X$ was amplified using glgXF and glgXR; $g \lg C$ was amplified using glgCF and glgCR; $g \lg A$ was amplified using glgAF and glgAR and $g \lg P$ was amplified using glgPF and glgPR (Additional file 1: Table $\mathrm{S} 2 \mathrm{~A})$. The control gene, cysG, was amplified using cysGF and cysGR (Additional file 1: Table S2A). The relative changes in gene transcription were calculated using the comparative CT method, normalized to the level of cysG transcript. Each set of qRT-PCRs was examined in duplicate and was repeated with at least two independent RNA preparations.

lodine vapor staining to detect glycogen in bacterial cells E. coli $\mathrm{DH} 5 \alpha$ strains were cultured in $1 \times \mathrm{M} 9$ minimal agar plates for 48 hours before being exposed to iodine vapor for staining to detect glycogen $[28,29]$. A colony accumulating branched polysaccharide is stained brown while that with linear polysaccharide is stained blue due $\alpha$-glucan helix complexation with iodine. Each agar plate was exposed to solid iodine flakes in a sealed glass beaker. The bottom of the beaker was heated inside the fume hood for about $1 \mathrm{~min}$ on a hot plate to generate iodine vapor. The plates were immediately removed when the colony color changed while the agar was still transparent (generally 30 seconds) to avoid over-staining.

\section{Glycogen extraction}

Glycogen was extracted from E. coli DH5 $\alpha$ strains by using a modified procedure described by Preiss et al. [30], which works equally well for both the branched molecule, glycogen, and its linear counterpart. E. coli $\mathrm{DH} 5 \alpha$ was cultured in $1 \mathrm{~L} 1 \times \mathrm{M} 9$ minimal medium at $37^{\circ} \mathrm{C}$ with gyratory shaking for $20 \mathrm{~h}$. Cells were harvested by centrifugation at $5,000 \times \mathrm{g}, 4^{\circ} \mathrm{C}$ for $10 \mathrm{~min}$ (Sorvall, SLA3000). Pellets were resuspended in $20 \mathrm{ml}$ of ice-cold $0.05 \mathrm{M}$ TEA buffer and sonicated on ice for $3 \mathrm{~min}$. Homogenized cell pellets were then centrifuged at $104,000 \times \mathrm{g}, 4^{\circ} \mathrm{C}$ for $90 \mathrm{~min}$ (Beckman, SW41Ti). Supernatant was discarded and pellets were resuspended in $20 \mathrm{ml} \mathrm{MilliQ} \mathrm{H}_{2} \mathrm{O}$. The resulting suspension was boiled in a water bath for $5 \mathrm{~min}$ to denature all proteins. The suspension was then centrifuged at $18,000 \times \mathrm{g}$ (Sorvall) for $10 \mathrm{~min}$. The supernatant (S1) was kept. The precipitate was treated the same way and the new supernatant (S2) was pooled with S1. A 0.1 volume of $50 \%$ trichloroacetic acid (TCA) was added to the pooled supernatant $(\mathrm{S} 1+\mathrm{S} 2)$ in order to precipitate other macromolecules (DNA, RNA, and protein, etc.). The solution was placed on ice for $10 \mathrm{~min}$, after which it was centrifuged at $18,000 \times \mathrm{g}$ for $10 \mathrm{~min}$. The supernatant was collected and mixed with 1.5 volume of absolute ethanol. Glycogen was precipitated on ice for $20 \mathrm{~min}$, after which it was centrifuged at 18,000 $\times \mathrm{g}$ for $10 \mathrm{~min}$. To purify the extracted glycogen, the pellet was dissolved in $5 \mathrm{ml}$ MilliQ $\mathrm{H}_{2} \mathrm{O}$ and $5 \mathrm{ml}$ ice-cold absolute ethanol was added. After incubating the solution at $4^{\circ} \mathrm{C}$ overnight, it was centrifuged at $18,000 \times \mathrm{g}$ for $10 \mathrm{~min}$. The supernatant was discarded and pellet was kept. This wash/ precipitation procedure was repeated two more times. Finally, the pellet was dissolved in acetone and left to completely air-dry at $37^{\circ} \mathrm{C}$.

\section{Ultraviolet-visible spectroscopy ( $\lambda$-max scanning)}

Following the method of Nakamura et al. [31], $1 \mathrm{mg}$ of glycogen extracted from each of the $E$. coli DH5 $\alpha$ strains was weighed to make a $10 \mu \mathrm{g} / \mu \mathrm{l}$ glycogen solution. A serial dilution of $150 \mu \mathrm{L}$ glycogen-iodine solution was prepared and transferred to a 96-well microplate. Blank controls were always kept, along with the test groups, by replacing glycogen solution with $\mathrm{dH}_{2} \mathrm{O}$. A microplate reader was used to scan the absorbance of the samples from $350 \mathrm{~nm}$ to $700 \mathrm{~nm}$.

\section{Glycogen content assay and comparison with protein content}

Glycogen content was assayed for each of the six E. coli $\mathrm{DH} 5 \alpha$ strains along their growth curves in $1 \times \mathrm{M} 9$ minimal medium $(\mathrm{T} / \mathrm{G}=1: 2)$ with three independent replicates. 
Procedures were followed as described by Dauvillee et al [17]. Protein content was assayed by reference to a standard curve based on bovine serum albumin $(0.25 \mathrm{mg} / \mathrm{ml}$ BSA and Coomassie Plus (Bradford)).

\section{Fluorophore-assisted carbohydrate electrophoresis (FACE) and $A C L$ determination}

FACE was used to analyze glycogen chain length distribution pattern. Glycogen was debranched as previously described [32]. The samples were dried in vacuo and reducing ends were labeled with the charged fluorophore 8-amino-1,3,6-pyrenetrisulfonic acid (APTS). Capillary electrophoresis was then used to resolve and detect the labeled oligosaccharides by increasing chain length. These procedures were performed according to Morell et al. [33]. The ACL of the glycogen was computed using the formula:

$$
\mathrm{ACL}=\frac{\sum \text { Length of Oligosaccharide Chain } \times \text { Molar Percentage }}{100}
$$

\section{Reducing end assay}

A maltotriose stock solution $(1 \mathrm{mg} / \mathrm{ml})$ was used to construct a maltotriose standard concentration curve (0 to $200 \mathrm{nmol}$ ), which was used as a reference for measuring reducing ends of $5 \mathrm{mg}$ glycogen samples. Each sample was debranched as described above. Branching frequency estimation of debranched starch was determined based on a reducing end assay [34] as modified by [35].

\section{Starvation assay}

E. coli $\mathrm{DH} 5 \alpha$ strains were cultured in $1 \times \mathrm{M} 9$ minimal medium at $37^{\circ} \mathrm{C}$ for 20 hours with gyratory shaking. Cells were harvested by centrifugation at $5,000 \times \mathrm{g}$ for 10 minutes and washed in PBS buffer 3 times. In order to avoid the influence of cell lysis on bacterial starvation survival, cells were diluted 100 times with PBS buffer and left on the bench-top. After $0,3,6,9,13$, and 15 days, colony-forming units (CFUs) for each strain were counted using the Miles and Misra method [36,37]. Two samples were measured for each strain at each time point.

\section{Desiccation assay}

The desiccation assay was conducted on each of the $E$. coli $\mathrm{DH} 5 \alpha$ strains by following the procedures as described in Walsh and Camilli [38], with modifications. In order to dry cells quickly in the laminar flow hood, the cells were concentrated 10 times in PBS buffer. A $15 \mu \mathrm{l}$ culture aliquot was spread evenly on the lid of a sterile Petri dish and air-dried inside the hood. Samples were obtained at $0,2,3,6,9$ hours by resuspending the dried cells in $1.5 \mathrm{ml}$ PBS buffer. Viable cells were counted as stated above in starvation assay. Four samples were measured for each strain at each time point.

\section{Cold stress assay}

Bacterial cultures were prepared the same way as for the desiccation experiments, except that the cell pellets were resuspended in $10 \mathrm{ml}$ PBS buffer instead of being concentrating 10 times. The suspension was serially and aseptically diluted in a hood from $10^{-1}$ to $10^{-8}$ times by mixing $100 \mu$ l diluted culture with $900 \mu \mathrm{l}$ PBS buffer. Since the original culture and $10^{-1}$ diluted culture had too high cell density, we started from $10^{-2}$ dilution until $10^{-7}$ dilution. Once the plates were dried, plates were wrapped into a sealed plastic bag and stored in a cold room $\left(4^{\circ} \mathrm{C}\right)$. For cold viability measurement, plates were taken out of the cold room at day $0,3,6,10$, and 13 and incubated at $37^{\circ} \mathrm{C}$ overnight. The colony forming units were counted and calculated the next day. Each count was repeated 3 times.

\section{Biofilm formation assay}

The procedure for biofilm formation ability was sourced from Merritt et al. [39], Narisawa et al. [40], and Burton et al. [41]. Greiner CELLSTAR ${ }^{\circledR} 96$ well plates (polystyrene, flat bottom with lid, sterile) were used. The E. coli DH5 $\alpha$ strains were cultured in LB and $1 \times \mathrm{M} 9$ minimal medium $(\mathrm{T} / \mathrm{G}=1: 2)$. The samples were stained with crystal violet. Results were obtained from three independent replicates.

\section{Results \\ Construction of in situ N-terminal truncated GlgB in E. coli DH5a}

In order to construct bacterial strains with the same genetic background but accumulating differential ACL glycogen, a suite of $E$. coli $\mathrm{DH} 5 \alpha$ strains with N-terminal progressively truncated GBEs was constructed in situ (Figure 1A). A deletion of 30 to 123 amino acids (AA) was achieved by homologous recombination of predesigned linear PCR products binding to the $\operatorname{glg} B$ gene [27]. In addition, a full $g l g B$ knockout strain (E. coli DH5 $\alpha \quad \Delta$ glgB) was also constructed. Sequencing and alignment of $g l g B$ in each $E$. coli DH5 $\alpha$ strain confirmed that no unanticipated mutations existed. However, insertion-deletion recombination leaves a scar sequence upstream of $g \lg B$ with a new ribosome-binding site (RBS) (Figure 1B), which replaces the original regulatory region.

\section{Influences of N-terminal truncation of glgB on transcription of the glgBXCAP operon}

Previously, glycogen metabolism genes in $E$. coli were considered to form two operons: $\operatorname{glg} B X$ and $g \operatorname{lgCAP}[4]$. It is now known that $\operatorname{glg} B X C A P$ consists of a single transcription unit with a sub-operon promoter within $g \lg C$ directing the expression of $g \lg A P$ [42]. Thus, 
manipulation of $\operatorname{glg} B$ may alter the expression, not only of $g \lg B$, but also the downstream genes, which can in turn affect glycogen structure and accumulation. In addition, the inserted scar sequence may also have unpredictable effects on $g \lg B$ expression. Quantitative RT-PCR showed that the $g \lg B, g \lg X, g \lg C, g \lg A$, and $\operatorname{glg} P$ in all the six $E$. coli $\mathrm{DH} 5 \alpha$ strains were expressed at $20 \mathrm{~h}$ except for the full $g \lg B$ knockout strain. Expression levels, averaged over the two biological and two technical replicates, normalized to the level of cysG, can be found in Table 1. There was a good correlation between transcription levels over the five genes of the glgBXCAP operon from the WT versus the corresponding genes in each of the mutants: E. coli $\mathrm{DH} 5 \alpha \operatorname{glgB} \Delta 90$ versus WT $\left(\mathrm{r}^{2}=0.91\right)$, E. coli $\mathrm{DH} 5 \alpha$ glgB $\Delta 180$ versus WT $\left(\mathrm{r}^{2}=0.79\right)$, E. coli $\mathrm{DH} 5 \alpha$ glgB $\Delta 270$ versus WT $\left(\mathrm{r}^{2}=\right.$ $0.58)$, E. coli $\mathrm{DH} 5 \alpha$ glgB $\Delta 369$ versus WT $\left(\mathrm{r}^{2}=0.93\right)$ and $E$. coli $\mathrm{DH} 5 \alpha \Delta \mathrm{glgB}$ versus WT $\left(\mathrm{r}^{2}=0.79\right)$. The effect of the sub-operon promoter can also been clearly seen in the substantially increased expression of $g l g C$, and to lesser extent, $g l g A$ and $g l g P$ (Table 1).

\section{Influence of GBE N-terminus on glycogen accumulation}

The amount of glycogen accumulation in the six E. coli DH5 $\alpha$ was observed through corresponding growth curves (Figure 2). glgB manipulation did not change bacterial growth rates (Figure $2 \mathrm{~A})$. Since $1 \times \mathrm{M} 9(\mathrm{~T} / \mathrm{G}=1: 2$ ) is a minimal medium, bacterial density could only reach a cell density around 0.9-1.0 $\left(\mathrm{OD}_{600}\right)$. A small peak of glycogen accumulation appeared at the 5th hour for all strains, and corresponded to the early exponential phase. After a further $3 \mathrm{hrs}$ of incubation, glycogen levels dropped to their lowest levels in late exponential phase, presumably because the glucose was more needed for growth than glycogen accumulation. After reaching stationary phase at $9 \mathrm{hrs}$, glycogen accumulation was maintained for another $10 \mathrm{hrs}$.

\section{Alteration of glycogen structure due to GBE N-terminal truncation}

The structure of the glycogen was further assessed using iodine staining and fluorophore-assisted carbohydrate

Table 1 Level of Gene Express for E. coli DH5a strains, averaged over 2 technical and 2 biological replicates, normalized to the level of cysG

\begin{tabular}{lllllll}
\hline Gene & $\boldsymbol{W} \boldsymbol{T}$ & $\mathbf{\Delta 9 0}$ & $\mathbf{\Delta 1 8 0}$ & $\mathbf{\Delta 2 7 0}$ & $\mathbf{\Delta 3 6 9}$ & $\mathbf{\Delta g} \boldsymbol{g} \boldsymbol{B}$ \\
\hline $\operatorname{glg} B$ & 1.20 & 3.71 & 9.32 & 11.20 & 3.86 & 0.08 \\
$\operatorname{glg} X$ & 0.68 & 1.66 & 3.83 & 4.07 & 2.42 & 7.83 \\
$\operatorname{glg} C$ & 6.07 & 8.34 & 13.51 & 12.19 & 10.96 & 16.55 \\
$\operatorname{glg} A$ & 2.08 & 1.71 & 4.19 & 5.18 & 2.82 & 4.86 \\
$\operatorname{glg} P$ & 2.82 & 3.52 & 6.99 & 5.68 & 3.44 & 3.85 \\
\hline
\end{tabular}

electrophoresis (FACE). Iodine staining is a frequently used method for detecting glycogen content and structure in microorganisms grown on agar plates [17]. The intensity of the stain corresponds with $\mathrm{ACL}$, whereby glycogen with short ACL stains a light-yellow in contrast to glycogen with long ACL which stains dark brown. $E$. coli $\mathrm{DH} 5 \alpha$ and glgB $\triangle 270$ appears as light-yellow colonies while $E$. coli $\mathrm{DH} 5 \alpha \operatorname{glgB} \Delta 90$, glgB $\Delta 180$, and $\operatorname{glgB} \Delta 369$ were dark brown. In contrast, $E$. coli $\mathrm{DH} 5 \alpha \Delta \mathrm{glgB}$ colonies were stained to dark blue, indicating the presence of amylose-like long linear $\alpha 1$,4-glucan polysaccharide (Additional file 1: Figure S1). $\lambda$-max scanning of glycogen-iodine complexes from each isolate over a wavelength range of 350-750 nm confirmed these conclusions (Additional file 1: Table S3) and concurred with previous findings [43]. The highest $\lambda$-max value of $585 \mathrm{~nm}$ was detected for strain $\Delta \mathrm{glgB}$, which is close to the absorbance of long linear $\alpha 1,4$-glucan amylose $(\sim 600 \mathrm{~nm})$, as compared to $405 \mathrm{~nm}$ for the wild type strain, which is close to the absorbance maximum for glycogen $(\sim 420 \mathrm{~nm})$. Thus according to the iodine vapor staining and $\lambda$-max scanning results, the $\mathrm{N}$-terminal truncation of $\mathrm{GlgB}$ altered the glycogen structure of $E$. coli DH5 $\alpha$.

FACE was used to compare chain length distributions of isoamylase debranched glycogen from the six E. coli DH5 $\alpha$ strains (Figure 3A). No oligosaccharides greater than 49DP were detected in any of the strains except for $E$. coli $\mathrm{DH} 5 \alpha \Delta \mathrm{glgB}$, where no measurements were recorded at all because, consistent with this being an essentially linear, amylose-like $\alpha 1,4$-glucan molecule, the DP had gone out to a chain length which cannot be directly detected by the instrument. The capillary electrophoresis instrument used in this study can typically measure debranched $\alpha 1,4$-glucan from DP6-80 [44]. Hence, the novel long linear chain glycogen synthesized by $\Delta \mathrm{glgB}$ has elongated to the point that it is already comparable to long linear chain amylopectin and amylose polymers [44], which we refer to here as 'amylose-like'. This is consistent with the classification based on iodine vapor staining and the reducing end assay (discussed below). A molar difference plot of FACE (Figure 3B), in which the values obtained for the wild type strain are subtracted from those of the mutant strains, was used to determine whether there are any changes to the glycogen structures from the N-terminal deleted GlgB-expressing strains. In order to better understand the FACE results, glycogen ACL (see Table 2) was calculated for each strain, averaged over two independent experiments using the formula provided in the Materials and Methods section. The ACL for WT glycogen was 12.35 DP, standard deviation 0.30 DP. On that basis, 5-11 DP can be characterised as having shorter ACL, while chains $13 \mathrm{DP}$ or greater can 

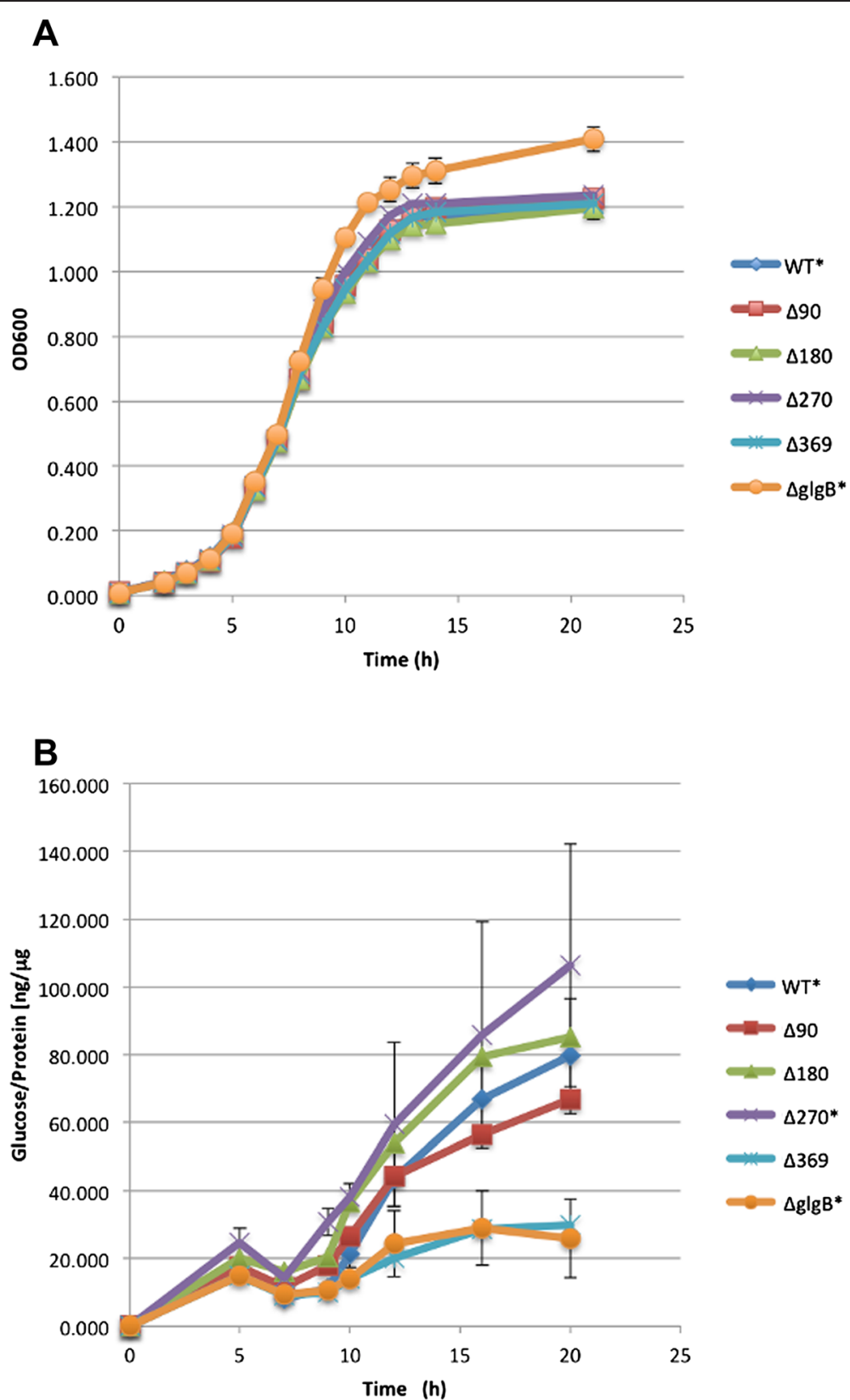

Figure 2 Growth of E. coli DH5a strains in $1 \times M 9$ minimal media ( $T / G=1: 2$ ) and corresponding glycogen accumulation. A. Cell density is plotted against time averaged over four independent $\mathrm{OD}_{600}$ readings. B. Glycogen accumulation is expressed as ratio of glucose to protein amount over time. Three independent replicates were performed. All data were presented as means \pm standard error.

be characterised as having longer ACL. A significant reduction in the proportion of shorter chains and an increase in the proportion of longer chains were observed in most of the mutant strains compared to the wild type. The glycogen in $\operatorname{glgB} \Delta 90$ had $34.1 \%$ short chains (versus $52.5 \%$ in the wild type strain) and $60.7 \%$ long chains (versus $40.4 \%$ in the wild type strain). For glycogen in $\operatorname{glgB} \Delta 180$, the corresponding percentages were $33.7 \%$ short chains and $60.8 \%$ long chains, while the glycogen in $\operatorname{glgB} \Delta 369$ had $37.7 \%$ short chains and $56.7 \%$ long chains. In a complete contrast to these, glycogen from glgB $\Delta 270$ had $47.4 \%$ short chains and $45.0 \%$ long chains which is not that different to the distribution in the wild type glycogen. The similarity between the glycogen from the glgB $\triangle 270$ strain and that from the parent, wild type strain is also evident in the molar percentage and molar difference plots. 


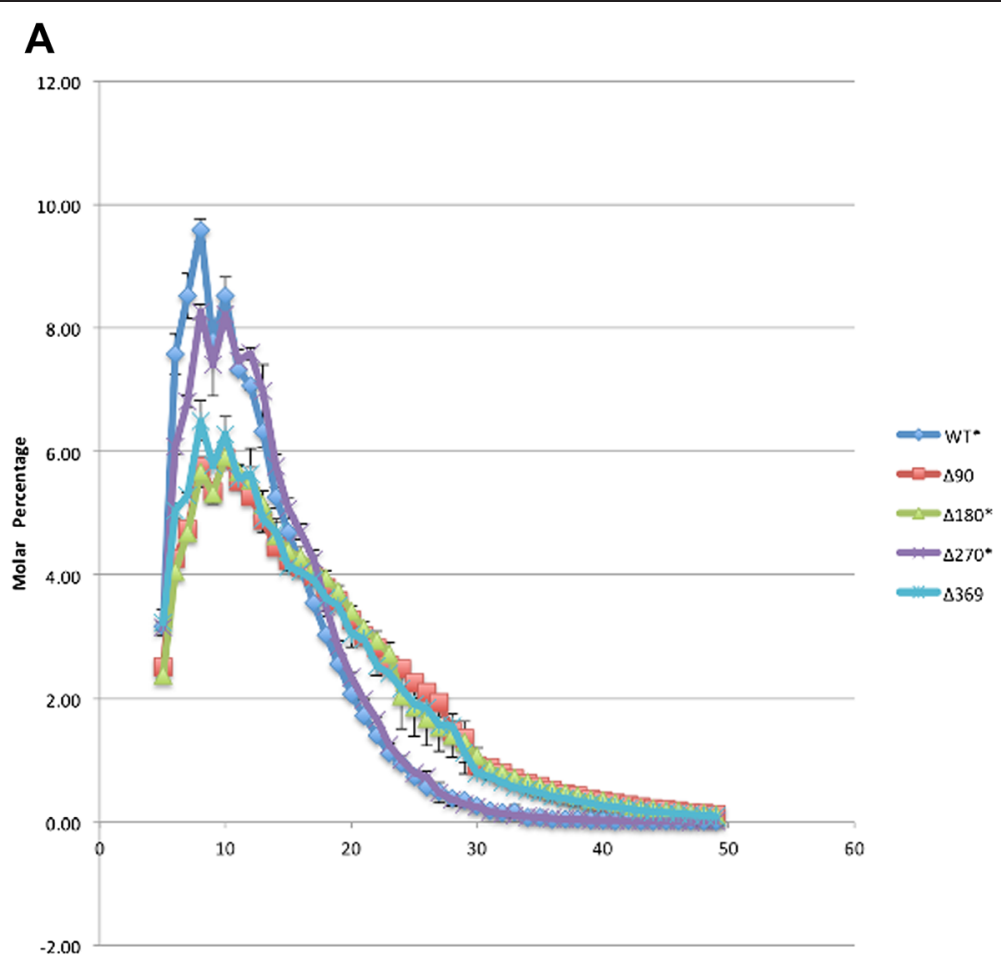

B

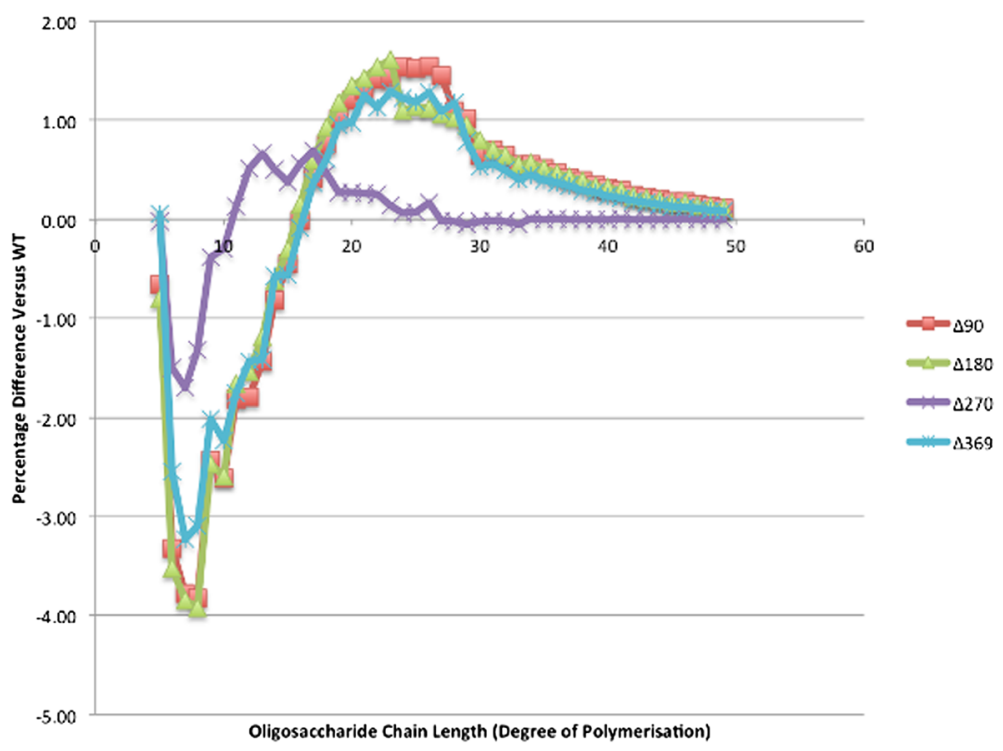

Figure 3 Chain length distributions of oligosaccharides in glycogen extracted from the six E. coli DH5a strains. A. Chain length distributions of isoamylase-debranched glycogen, which are expressed as molar percentage (\%) in terms of oligosaccharide chain length. B. Difference plot generated by subtracting the molar percentage of the respective WT oligosaccharide DP from the corresponding $g \operatorname{lgB} \Delta 90, \mathrm{glgB} \Delta 180, \mathrm{glgB} \Delta 270$, and glgB $\Delta 69$ molar percentages. The experiment was performed twice independently with two repeats for each replicate.

Reducing end assay of amylose-like 'glycogen' from E. coli DH5 $\alpha \Delta$ glgB demonstrated that the branching frequency in the polysaccharide was significantly reduced and as low as $6.7 \mathrm{nmol}$ of maltotriose equivalent, while the branching frequency in the commercial oyster glycogen is $537.7 \mathrm{nmol}$ of maltotriose equivalent (Additional file 1: Figure S2). This further confirms that the amylose-like glycogen of $\Delta \operatorname{glgB}$ does not just have significantly longer ACL but it is also significantly less branched hence really comparable in structure to long chain amylopectin or amylose. 
Table 2 Average chain length of glycogen extracted from each of E. coli DH5a strains based on FACE data, across 2 biological and, for each of these, 2 technical replicates

\begin{tabular}{llll}
\hline $\begin{array}{l}\text { E. coli } \\
\text { DH5a } \\
\text { strain }\end{array}$ & \multicolumn{3}{l}{ Average chain length (Glucosyl Residues) } \\
\cline { 2 - 4 } & Replicate $\mathbf{1}$ & Replicate $\mathbf{2}$ & Average \\
\hline WT & 12.35 & 11.90 & 12.13 \\
glgB $\mathbf{\Delta} \mathbf{9 0}$ & 16.64 & 16.01 & 16.33 \\
glgB $\mathbf{\Delta} \mathbf{1 8 0}$ & 16.53 & 18.25 & 17.39 \\
glgB $\mathbf{\Delta} \mathbf{2 7 0}$ & 12.83 & 12.82 & 12.83 \\
glgB $\mathbf{\Delta 3 6 9}$ & 15.76 & 14.70 & 15.23 \\
\hline
\end{tabular}

\section{Starvation survival assay}

To study the influence of GBE N-terminal truncation on E. coli starvation survival, strains were suspended in PBS buffer for 15 days. Colony forming unit counts were recorded to create a starvation survival curve (Figure 4). At day 3, E. coli DH5 a wild-type was down to $58.4 \%$ of the starting count, but the mutated stains fared considerably worse, with viabilities down to $34.7 \%$ (glgB $\triangle 90$ ), $26.0 \%$ (glgB $\Delta 180), 30.3 \%(\operatorname{glgB} \Delta 270), 35.5 \%(\operatorname{glgB} \Delta 369)$ and $21.5 \%$ $(\triangle \mathrm{glgB})$. However, at the day 6 mark all the strains had similar viability to the parent strain $(12.6 \%-16.5 \%$ for the mutated strains versus $20.5 \%$ for the wild type).

\section{Desiccation resistance}

Since glycogen can be converted to trehalose [12], we considered whether the differences in glycogen structure within the mutants would affect the trehalose production pathway. To test this hypothesis, we investigated desiccation tolerance, which has been shown to be dependent upon trehalose accumulation $[13,45]$. Both the wild type and mutant strains died rapidly in the first $3 \mathrm{hrs}$. The wild type strain CFU count was $0.024 \%$ of the starting value. The mutated strains had similar counts. The counts halved again in the next 6 hours. More importantly, there was little difference between wild type and most of the mutated strains, though $\Delta \mathrm{glgB}$ fared worse than the other strains, most clearly at the $6 \mathrm{hr}$ time point (Figure 5).

\section{Cold stress assay}

The situation with the desiccation stress assay was mirrored in the cold stress assay, with all the strains dying rapidly, though once again $\Delta \mathrm{glgB}$ fared worse than the other strains at the $6 \mathrm{hr}$ time point despite starting with a greater CFU count at the outset. The glgB $\triangle 369$ strain also showed this pattern (Additional file 1: Figure S5).

\section{Biofilm formation assay}

Two types of media, LB and $1 \times \mathrm{M} 9$ minimal medium $(\mathrm{T} / \mathrm{G}=1: 2)$, were used for comparison. For E. coli $\mathrm{DH} 5 \alpha$ strains cultured in $1 \times \mathrm{M} 9$ minimal medium no significant difference was observed among the strains (data not shown). On the other hand, comparison of LB and $1 \times$ M9 minimal medium $(\mathrm{T} / \mathrm{G}=1: 2)$ showed that $\mathrm{LB}$ broth greatly improves bacterial biofilm formation

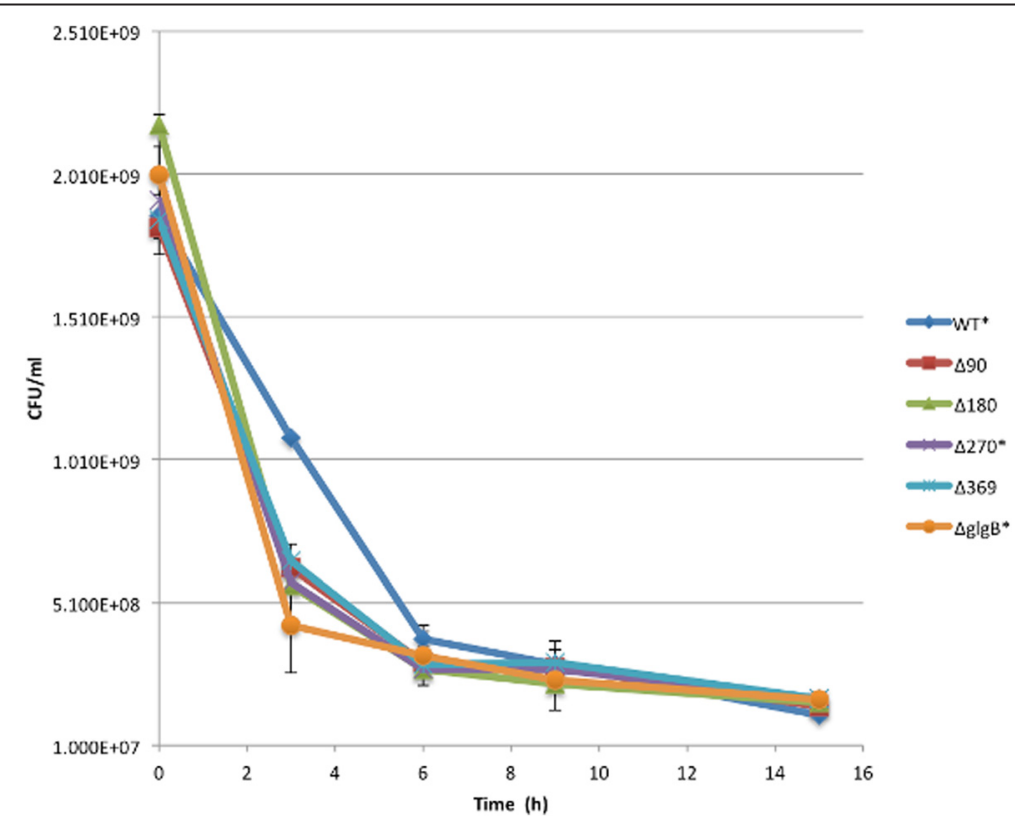

Figure 4 Starvation survival assay for E. coli DH5a strains in PBS buffer for 15 days. For each strain, two independent replicates were performed. Each replicate includes. four repeats. Viable cells of the six strains drop sharply for the first six days. E. coli DH5a survived better, especially at day 3, than E. coli $\mathrm{DH} 5 \mathrm{a} \Delta \mathrm{glgB}$ from day 0 to 9 . The other four strains behaved similar with no obvious difference. After day 6, cells died at a very slow rate. At day 15, the number of colony-forming units (CFU) for the six E. coli DH5a strains converged together. 


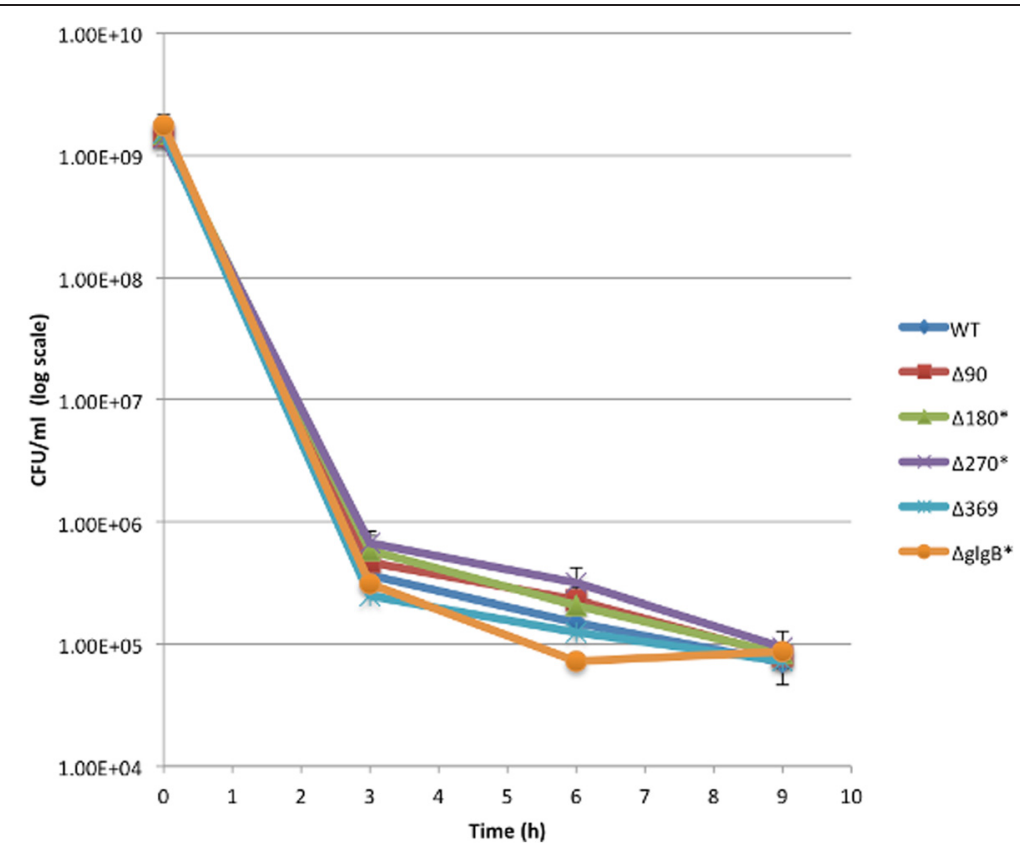

Figure 5 Desiccation survival abilities of E. coli DH5a strains. Counts of colony-forming units (CFU) are plotted for each strain at time point 0 h, $3 \mathrm{~h}$, and $6 \mathrm{~h}$. Two independent biological replicates were performed for each strain at each time point. For each replicate, four technical repeats were included.

abilities, though this is to be expected given the nature of the two media. Overall, the biofilm forming abilities of wild type E. coli $\mathrm{DH} 5 \alpha$ and the $\Delta \mathrm{glgB}$ strain were not significantly different (given experimental errors), across 3 repeats involving 2 different media. However, point for point across the three experiments the biofilm forming capabilities of the $\Delta \mathrm{glgB}$ strain were greater than that of the wild type strain, which is significant based on a two tail binomial distribution statistic. Finally, the most surprising result was that E. coli DH5 $\alpha$

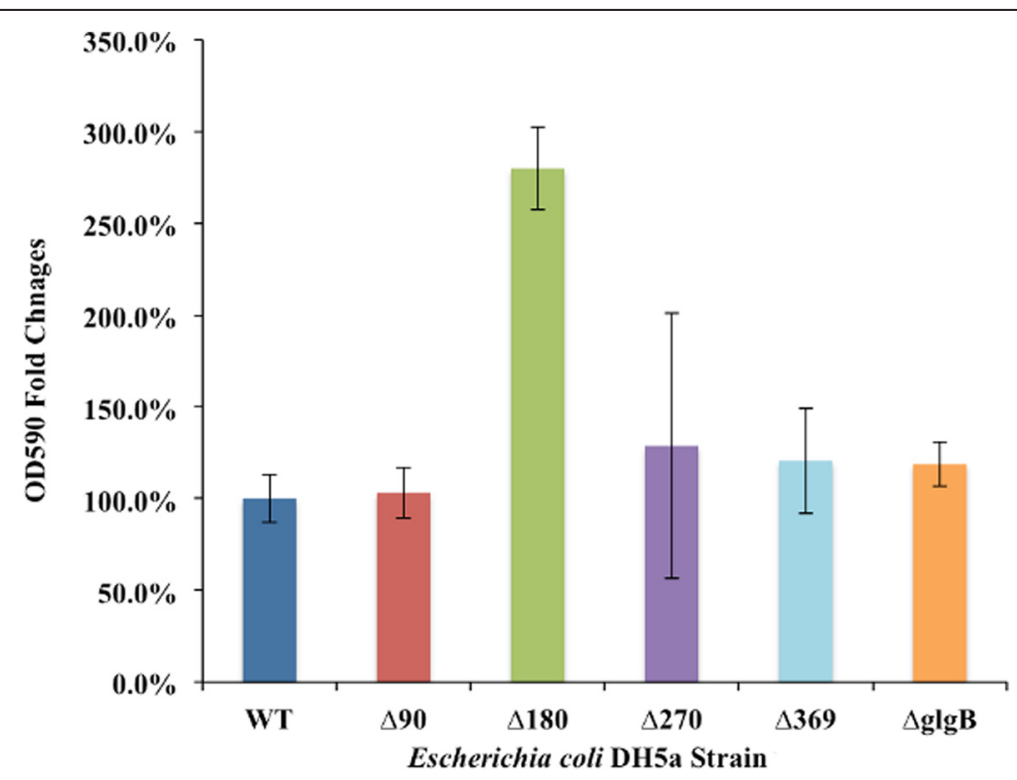

Figure 6 Quantification of biofilm formation abilities of E. coli DH5a strains on 96-well polystyrene plates in LB. Crystal violet staining method is used. Findings are expressed as fold changes versus WT based on based on average of three independent replicates. Bacteria in LB broth had enhanced biofilm formation abilities compared to bacteria growing in $M 9(T / G=1: 2)$, where biofilm formation abilities were uniform (including $\Delta 180)$, but a quarter of the level of that seen for the strains cultured in LB broth (Data not shown). 
glgB $\triangle 180$ in LB broth showed a significant increase in biofilm formation (Figure 6).

\section{Discussion}

The N-terminus of $E$. coli GBE influences the chain length distribution of glycogen, consistent with the previous in vitro study [23]. However, unlike the earlier in vitro experiment [23], no strong correlation between progressive shortening of $\mathrm{N}$-terminus and gradual increase of transferred oligosaccharide chains was observed. Our results (Figure 3A) showed that glycogen samples from $E$. coli $\mathrm{DH} 5 \alpha$ glgB $\Delta 90$, E. coli $\mathrm{DH} 5 \alpha$ glgB $\Delta 180$, and E. coli DH5 $\alpha$ glgB $\Delta 369$ have similar glycogen chain length distribution patterns (also reflected in similar ACLs in Table 2), while glycogen from $E$. coli $\mathrm{DH} 5 \alpha$ glgB $\Delta 270$ has a distribution pattern that is between the wild type and the other mutant strains, with a reduced percentage of 5-10DP oligosaccharides and increased percentage of 11-26 DP oligosaccharides (Figure 3B). No difference in chain length distribution was observed beyond 26DP between the $E$. coli $\mathrm{DH} 5 \alpha \operatorname{glgB} \Delta 270$ and the wild type strain.

The observed difference of chain length distributions caused solely by $\mathrm{N}$-terminal truncated GBEs in in vitro study [23] is probably compensated by enzymes such as $\mathrm{GlgP}$ and $\mathrm{GlgX}$ in vivo. Chain length distribution patterns of glycogen samples indicate that the six E. coli DH5 $\alpha$ strains can be divided into three groups: E. coli DH5 $\alpha(\mathrm{ACL}=12.13 \mathrm{DP})$ and E. coli $\mathrm{DH} 5 \alpha$ glgB $\Delta 270$ $(\mathrm{ACL}=12.83 \mathrm{DP})$ form Group 1 , E. coli $\mathrm{DH} 5 \alpha \operatorname{glgB} \Delta 90$ $(\mathrm{ACL}=16.33 \mathrm{DP}), \quad$ E. coli $\mathrm{DH} 5 \alpha$ glgB $\Delta 180 \quad(\mathrm{ACL}=$ 17.39DP), and $E$. coli $\mathrm{DH} 5 \alpha$ glgB $\Delta 369(\mathrm{ACL}=15.23 \mathrm{DP})$ belong to Group 2, and finally E. coli $\mathrm{DH} 5 \alpha \Delta \mathrm{glgB}$ (ACL not available due to its linear structure) forms Group 3.

In this study, we confirm that, apart from glycogen content, glycogen structure also has an impact on iodine staining (Additional file 1: Figure S1). An earlier study only focused on the relationship between amylose chain length and iodine staining [46], according to which longer chain length leads to absorbance at comparatively higher wavelengths $(\lambda$-Max). Iodine vapor staining has frequently been used to detect glycogen content, while glycogen structure (ACL) was largely ignored [16];Lerner, 2009 \#1353\}, although Dauvillee et al. [17] mentions that iodine staining can provide information about the structure of glycogen or starch. In this study, we showed that $\lambda$-Max of glycogen-iodine solution (Additional file 1: Table S3) is related to glycogen ACL (Table 2) with longer ACL generating darker brown colour. Moreover, the classification of E. coli $\mathrm{DH} 5 \alpha$ strains based on iodine vapor staining (Additional file 1: Figure S1) is consistent with the classification by FACE (Figure 3).

Unexpectedly, the strain E. coli $\mathrm{DH} 5 \alpha$ glgB $\Delta 270$ exhibited a significant level of GBE activity compared to other mutants. Despite having 39 residues truncated at $\mathrm{N}$-terminus there were minimal changes in chain transfer pattern and substrate preference [47]. It had been assumed that the 39 residues are without specific function. It was also suggested that the activity of GlgB is reduced in proportion to the number of amino acids truncated, based on the study of three truncated GlgBs (GlgB $\Delta 112, \Delta 121$, and $\Delta 171)$ from $M$. tuberculosis $H 37 R v$ [48]. As mentioned earlier, such a relationship was not observed in the current study, which requires further exploration for an accurate explanation. A potential explanation is that some $\mathrm{N}$-terminal truncations lead to previously unidentified and beneficial foldings for GBE so that it became catalytically more active compared to the other N-terminal truncated GBEs. A recent study also found that four enzymes in deoxyxylulose phosphate pathway (DXP) are highly insoluble, which affects metabolite formation, while increased solubility of enzymes provides a 'strategy to increase the production of secondary metabolites' [49]. Thus, $\mathrm{N}$-terminal truncation induced enzyme solubility may be one of reasons for the enzyme's functional improvement.

Bacterial GBEs can be divided into two groups according to the lengths of their N-terminus [24]. We collected a set of 1035 GBE sequences belonging to different bacterial species from Uniprot database [50] to determine the distribution of GBE lengths, and found that two apparent peaks exist with about 100 AA difference (see Additional file 1: Figure S3). These peaks are in agreement with earlier findings that GBEs can be divided into Group 1 (both $\mathrm{N}_{1}$ and $\mathrm{N}_{2}$ modules present) and Group 2 (only $\mathrm{N}_{2}$ module present), according to the composition of $\mathrm{N}$-terminus [51]. In addition, the $\mathrm{N}_{1}$ module is hypothesized to originate from the duplication of $\mathrm{N}_{2}$ module [51]. Recently the $\mathrm{N}_{2}$ module has been re-annotated as a carbohydrate-binding module (CMB48) [20], while the function of the $\mathrm{N}_{1}$ module is still not clear. Interestingly, the $\mathrm{N}_{1}$ module in $E$. coli is defined as the first 106 AA residues [24,51]. However, an alignment of the Pfam hidden Markov model (HMM) CMB_48 [52] starts at position 124, suggesting that $\mathrm{N}_{1}$ could span as much as the first 123 AA.

In any case, although a structure has been determined for $E$. coli $\mathrm{GlgB}(1 \mathrm{~m} 7 \mathrm{x})$ it only starts at residue 113; the full-length protein could not be crystalised and the structure of the N-terminal residues remains undefined [53].

Because the amount of glycogen accumulation is an important factor for bacterial survival [6], the influence of N-terminal truncation of GlgB on glycogen accumulation was also investigated by measuring glycogen content in cells (Figure 2). Growth curves show no significant differences among strains (Figure 2A). Thus, $\lg B$ is not essential for bacterial growth [54] because its complete abolition is not lethal. However, the $\mathrm{N}$-terminus 
of GlgB is involved in glycogen accumulation (Figure 2B). Ranking of glycogen content from high to low amount at $20 \mathrm{~h}$ for the six strains is $E$. coli DH $5 \alpha$ glgB $\Delta 270$, followed by $E$. coli $\mathrm{DH} 5 \alpha$ glgB $\Delta 180$, E. coli $\mathrm{DH} 5 \alpha$ wild type, $E$. coli $\mathrm{DH} 5 \alpha \operatorname{glgB} \Delta 90$, E. coli $\mathrm{DH} 5 \alpha$ glgB $\Delta 369$, and E. coli $\mathrm{DH} 5 \alpha$ $\triangle \mathrm{glgB}$. A previous report has confirmed that $g \lg B$-deficient E. coli accumulates a very low-level of glycogen [55]. By also looking at Table 1 (top row), it is interesting to see that glycogen amount is highest in E. coli $\mathrm{DH} 5 \alpha$ $\operatorname{glg} \mathrm{B} \Delta 270$, which corresponds to the strain with the highest transcription of the corresponding $\mathrm{N}$-truncated gene. E. coli $\mathrm{DH} 5 \alpha$ glgB $\Delta 180$ follows this pattern, but then $E$. coli $\mathrm{DH} 5 \alpha \operatorname{glgB} \Delta 90$ and wild type $E$. coli $\mathrm{DH} 5 \alpha$ do not quite follow the pattern and $E$. coli $\mathrm{DH} 5 \alpha$ glgB $\Delta 369$ is out of place with a higher level of expression that $E$. coli DH $5 \alpha$ glgB $\Delta 90$ or wild type E. coli DH5 $\alpha$.

The glycogen accumulation ability of E. coli $\mathrm{DH} 5 \alpha$ $\operatorname{glg} B \Delta 369$ is observed to be comparatively low and very close to that of $E$. coli $\mathrm{DH} 5 \alpha \Delta \mathrm{glgB}$, indicating that GBE in $E$. coli $\mathrm{DH} 5 \alpha \operatorname{glgB} \Delta 369$ is less functional compared to other N-terminal truncated strains. Specifically, GBEs in the other three $\mathrm{N}$-terminal truncated strains are only manipulated in N1 module while N2 module could still replace N1 module for essential functions, considering that N1 module is originated from duplication of N2 module. However, for GBE in E. coli $\mathrm{DH} 5 \alpha$ glgB $\Delta 369$, both N1 and N2 modules are potentially affected. Thus, no compensation mechanism is available for this truncated GBE. However, since we can still detect chain length distribution for glycogen in this strain, GBE in E. coli $\mathrm{DH} 5 \alpha$ glgB $\Delta 369$ still retains some of its branching activity.

Our original purpose was to alter glycogen ACL solely by manipulating GBE N-terminus in order to test the influences of glycogen ACL on bacterial durability in face of abiotic stress. However, by truncating GBE N-terminus, we found that glycogen ACL and accumulation are interrelated, which leads to the difficulty in drawing a definite conclusion about which is the major factors influencing bacterial durability. In our results, we did not see any difference among the four N-terminal truncated strains in terms of starvation resistance (Figure 4). However, compared to the survival rate of the wild type strain, GBE N-terminal truncation damaged bacterial starvation ability. That said, the deletion strain fared worst, suggesting that possessing glycogen, rather than amylose-like polysaccharide, is an advantage. It is intriguing that the highest level of glycogen with comparatively short $\mathrm{ACL}$ in $E$. coli $\mathrm{DH} 5 \alpha$ glgB $\triangle 270$ does not show any advantage in starvation survival. For desiccation resistance, E. coli $\mathrm{DH} 5 \alpha$ glgB $\Delta 90$, E. coli $\mathrm{DH} 5 \alpha$ glgB $\Delta 180$, and E. coli $\mathrm{DH} 5 \alpha$ glgB $\Delta 270$ show higher ability than $E$. coli DH5 $\alpha$ (see Figure 5), which may be ascribed to faster degradation of glycogen due to longer glycogen ACLs, though this explanation does not account for $\operatorname{glg} B \Delta 270$. The released glucose may be used for the synthesis of trehalose for stress protection. Although glycogen ACL in E. coli $\mathrm{DH} 5 \alpha$ glgB $\triangle 369$ is also longer than that in E. coli $\mathrm{DH} 5 \alpha$, the amount of glycogen is much lower in this strain. In addition, glycogen content itself has also been linked with stress resistance ability regardless of the impairment of glycogen degradation pathway $[5,25]$. High glycogen content results in a significant increase in intracellular water volume, which is beneficial for bacterial desiccation survival [56]. While our studies have shown that $\mathrm{N}$-terminal truncation enhances bacterial desiccation resistance, depending on both glycogen ACL and amount, further investigation is required to tease out the individual effects of glycogen structure and content. Here again, the deletion strain fared worst, a pattern we also noted in the low temperature $\left(4^{\circ} \mathrm{C}\right)$ viability assays.

Finally, biofilm formation was assayed across the set of strains. Biofilm formation is widely recognized as an important strategy for bacteria to survive and persist in harsh environmental conditions [26]. Cells are normally enclosed in a polymer matrix consisting of DNA, protein, and polysaccharides [57]. A study of Salmonella enteritidis demonstrated that "biofilm was formed from glycogen cell stores" [8]. A recent study also showed that glgP deficiency compromises biofilm formation of Azospirillum brasilense Sp7 [25]. The global regulatory protein $c s r A$, that is involved in glycogen biosynthesis, is also confirmed to control the formation and dispersal of biofilms in $E$. coli [58]. Since N-terminal truncation of GlgB changes glycogen ACL and accumulation, we decided to investigate whether GlgB $\mathrm{N}$-terminal truncation has any influence on $E$. coli DH5 $\alpha$ biofilm formation ability. Bacteria in LB broth had enhanced biofilm formation abilities compared to bacteria growing in M9 $(\mathrm{T} / \mathrm{G}=1: 2)$, where biofilm formation abilities were uniform, but at a quarter of the level of that seen for the strains cultured in LB broth. This is supported by a previous study that showed that glucose inhibition of biofilm formation is common for Enterobacteriaceae genus [59]. In contrast to our observations based on $E$. coli, a positive correlation between glycogen concentration and biofilm formation has been reported in Salmonella enteritidis SE3934 [8]. Thus, the effects of glucose on biofilm formation seem to vary in different microbial species, though the medium in which the bacteria are grown is clearly a factor. Biofilm forming ability was also uniform across the LB broth experiments, except for $E$. coli $\mathrm{DH} 5 \alpha$ glgB $\Delta 180$, which showed significantly enhanced biofilm formation ability. This is noteworthy, but requires further investigation to determine the underlying mechanisms. However, with the exception of the glgB $\Delta 180$ result in LB broth, the fact that the biofilm forming ability of $\Delta \mathrm{glgB}$ strain was at the same level as 
the other strains suggests that it is the presence of a long chain polysaccharide that is important for biofilm formation, rather than its structure. One final comment is appropriate at this point: we have, arguably, extracted as much as one can from E. coli $\mathrm{DH} 5 \alpha$, and now propose that more unequivocal results would have been obtained with a less labile starting species.

\section{Conclusions}

Despite $g \lg B$ being the first gene of an operon, it is clear that in situ mutation is a viable means to create more biologically relevant mutant strains. Secondly, there was the suggestion in the data that impairments of starvation, cold and desiccation resistance were worse for the strain lacking $g l g B$, though the first of these was not statistically significant. The results provide prima facie evidence linking abiotic stress tolerance with shorter glycogen ACL. However, further work needs to be done, perhaps in a less labile species. Further work is required to establish why glgB $\triangle 270$ was efficient at producing shorter ACL glycogen, and why the strain glgB $\Delta 180$ showed increased ability to form biofilms. Finally, further work is also required to tease out the complex relationship between glycogen abundance and glycogen structure.

\section{Additional file}

Additional file 1: Figure S1. Results of iodine vapor staining of $E$. coli DH5a colonies growing on M9 minimal agar plates. a-f represent the six E. coli DH5a strains as annotated above. Based on the staining color, we divided the six strains into three groups arbitrarily. $a$ and $d$ belong to group 1 with light yellow-brownish color. b, c, and e are classified as group 2 with dark brownish color. $f$ belongs to group 3 with dark blue color. Figure S2. Comparison of reducing ends in four polysaccharides: amylose, amylopectin, oyster glycogen, and glycogen from full glgB knockout strain E. coli DH5a $\Delta \mathrm{glgB}$. Three replicates were performed for each sample. Figure S3. Length distribution of bacterial GBEs. 1035 GBEs were selected from UniProt database under the name of "glycogen branching enzyme" or "1,4-alphaglucan branching enzyme". Each item was from a unique bacterial species while redundant or fragment sequences were removed manually or by nrdb90.pl. $\mathrm{R}$ was used to plot the histogram. Two major GBE groups can be identified in the figure, which shows consistent pattern with the result of Lo Leggio et al [53]. Figure S4. Cold stress $(40 \mathrm{C})$ tolerance assay. Strains were sampled at days 3, 6, 10 and 13, with 3 replicates at each data point. Error bars are +/- 1 standard deviation. Table S1. Bacterial strains used in this study. Table S2A. List of primers used in this study. Table S2B. List of primer pairs for the respective glgB deletion mutant stains. Table S3. Results of $\lambda$-max scanning ( $350 \mathrm{~nm}-750 \mathrm{~nm}$ ) of glycogen-iodine solutions.

\section{Abbreviations}

ACL: Average chain length; FACE: Fluorophore-assisted carbohydrate electrophoresis; GBE: Glycogen branching enzyme.

\section{Competing interests}

The authors declare that they have no competing interests.

\section{Authors' contributions}

LW wrote the paper, designed the experiments, and analyzed the data. AR assisted with the glycogen experimental designs, experiment troubleshooting, and data analysis. VMB assisted with the bacterial viability assays, interpretation of glycogen structure data, and GRT-PCR, growth curve and related data analysis. BK-H assisted with the iodine vapor staining, media optimisation and measurement of glycogen accumulation. OL assisted with the glycogen structure analysis (FACE) experiments (FACE) and systems for sample handling. CK assisted with the mutant construction and manuscript writing. MJW co-wrote the paper, performed additional data analysis and supervised the overall project. All authors read and approved the final manuscript.

\section{Acknowledgements}

We thank Dr. Harry Sakellaris (Griffith University), Dr. Steve Munyard (University of Western Australia), and Dr. Qiang Lee (University of Western Australia) for helping with E. coli DH5a mutant constructions. We also thank Ms. Suzhi Li (Plant Industry at CSIRO, Canberra) for helping with glycogen extraction and gene sequencing. We acknowledge Ms. Min Huang, Ms. Hong Wang, and Dr. Jixun Luo in Dr. Zhongyi Li's group (Plant Industry at CSIRO, Canberra) for technical support for glycogen and protein analysis. LW would like to thank Dr. Matthew Morrell for his arrangement of an industrial traineeship at CSIRO for half a year, during which time much of the work described here was carried out. Finally, LW gratefully acknowledges the UWA China Scholarship that funded his studies.

\section{Author details}

${ }^{1}$ School of Pathology and Laboratory Medicine, University of Western Australia, Perth, Australia. ${ }^{2} \mathrm{CSIRO}$ Agriculture Flagship, Canberra, Australia. ${ }^{3}$ International Rice Research Institute, Los Baños, Philippines. ${ }^{4}$ School of Chemistry and Biochemistry, University of Western Australia, Perth, Australia.

Received: 24 December 2014 Accepted: 1 April 2015

Published online: 07 May 2015

\section{References}

1. Wilson WA, Roach PJ, Montero M, Baroja-Fernandez E, Munoz FJ, Eydallin G, et al. Regulation of glycogen metabolism in yeast and bacteria. Fems Microbiol Rev. 2010;34(6):952-85.

2. Preiss J. Glycogen Biosynthesis. In: Schaechter M, editor. Encyclopedia of Microbiology. 3rd ed. Oxford: Elsevier; 2009. p. 145-58.

3. Wang L, Wise MJ. Glycogen with short average chain length enhances bacterial durability. Naturwissenschaften. 2011;98(9):719-29.

4. Cho KM, Lim WJ, Math RK, Islam SMA, Hong SJ, Kim H, et al. Comparative analysis of the glg operons of Pectobacterium chrysanthemi PY35 and other prokaryotes. J Mol Evol. 2008;67(1):1-12.

5. Bourassa L, Camilli A. Glycogen contributes to the environmental persistence and transmission of Vibrio cholerae. Mol Microbiol. 2009;72(1):124-38.

6. Strange RE. Bacterial glycogen and survival. Nature. 1968;220(5167):606-7.

7. Henrissat B, Deleury E, Coutinho PM. Glycogen metabolism loss: a common marker of parasitic behaviour in bacteria? Trends Genet. 2002;18(9):437-40.

8. Bonafonte MA, Solano C, Sesma B, Alvarez M, Montuenga L, Garcia-Ros D, et al. The relationship between glycogen synthesis, biofilm formation and virulence in Salmonella enteritidis. Fems Microbiol Lett. 2000;191(1):31-6.

9. Jones SA, Jorgensen M, Chowdhury FZ, Rodgers R, Hartline J, Leatham MP, et al. Glycogen and maltose utilization by Escherichia coli O157:H7 in the mouse intestine. Infect Immun. 2008;76(6):2531-40.

10. McMeechan A, Lovell MA, Cogan TA, Marston KL, Humphrey TJ, Barrow PA. Glycogen production by different Salmonella enterica serotypes: contribution of functional glgC to virulence, intestinal colonization and environmental survival. Microbiology. 2005;151(Pt 12):3969-77.

11. Pan YT, Carroll JD, Asano N, Pastuszak I, Edavana VK, Elbein AD. Trehalose synthase converts glycogen to trehalose. FEBS J. 2008;275(13):3408-20.

12. Chandra G, Chater KF, Bornemann S. Unexpected and widespread connections between bacterial glycogen and trehalose metabolism. Microbiology. 2011;157:1565-72.

13. Kandror O, DeLeon A, Goldberg AL. Trehalose synthesis is induced upon exposure of Escherichia coli to cold and is essential for viability at low temperatures. P Natl Acad Sci USA. 2002:99(15):9727-32.

14. Reina-Bueno M, Argandona M, Nieto JJ, Hidalgo-Garcia A, Iglesias-Guerra F, Delgado MJ, et al. Role of trehalose in heat and desiccation tolerance in the soil bacterium Rhizobium etli. Bmc Microbiol. 2012;12:207.

15. Ball SG, Morell MK. From bacterial glycogen to starch: understanding the biogenesis of the plant starch granule. Annu Rev Plant Biol. 2003;54:207-33. 
16. Alonso-Casajus N, Dauvillee D, Viale AM, Munoz FJ, Baroja-Fernandez E, Moran-Zorzano MT, et al. Glycogen phosphorylase, the product of the glgP gene, catalyzes glycogen breakdown by removing glucose units from the nonreducing ends in Escherichia coli. J Bacteriol. 2006;188(14):5266-72.

17. Dauvillee D, Kinderf IS, Li ZY, Kosar-Hashemi B, Samuel MS, Rampling L, et al. Role of the Escherichia coli glgX gene in glycogen metabolism. J Bacteriol. 2005;187(4):1465-73.

18. Tzvetkov M, Klopprogge C, Zelder O, Liebl W. Genetic dissection of trehalose biosynthesis in Corynebacterium glutamicum: inactivation of trehalose production leads to impaired growth and an altered cell wall lipid composition. Microbiol-Sgm. 2003;149:1659-73.

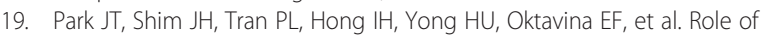
Maltose Enzymes in Glycogen Synthesis by Escherichia coli. J Bacteriol. 2011;193(10):2517-26.

20. Palomo M, Kralj S, van der Maarel MJEC, Dijkhuizen L. The unique branching patterns of Deinococcus glycogen branching enzymes are determined by their N-terminal domains. Appl Environ Microbiol. 2009;75(5):1355-62.

21. Guan HLP, Imparl-Radosevich J, Preiss J, Keeling P. Comparing the properties of Escherichia coli branching enzyme and maize branching enzyme. Arch Biochem Biophys. 1997;342(1):92-8.

22. Binderup M, Mikkelsen $\mathrm{R}$, Preiss J. Truncation of the amino terminus of branching enzyme changes its chain transfer pattern. Arch Biochem Biophys. 2002;397(2):279-85.

23. Devillers $\mathrm{CH}$, Piper ME, Ballicora MA, Preiss J. Characterization of the branching patterns of glycogen branching enzyme truncated on the N-terminus. Arch Biochem Biophys. 2003;418(1):34-8.

24. Hilden I, Leggio LL, Larsen S, Poulsen P. Characterization and crystallization of an active $\mathrm{N}$-terminally truncated form of the Escherichia coli glycogen branching enzyme. Eur J Biochem. 2000;267(8):2150-5.

25. Lerner A, Castro-Sowinski S, Lerner H, Okon Y, Burdman S. Glycogen phosphorylase is involved in stress endurance and biofilm formation in Azospirillum brasilense Sp7. Fems Microbiol Lett. 2009;300(1):75-82.

26. Hall-Stoodley L, Costerton JW, Stoodley P. Bacterial biofilms: from the natural environment to infectious diseases. Nat Rev Microbiol. 2004;2(2):95-108.

27. Datsenko KA, Wanner BL. One-step inactivation of chromosomal genes in Escherichia coli K-12 using PCR products. Proc Natl Acad Sci USA. 2000;97(12):6640-5.

28. Wilson WA, Wang Z, Roach PJ. Systematic identification of the genes affecting glycogen storage in the yeast Saccharomyces cerevisiae - Implication of the vacuole as a determinant of glycogen level. Mol Cell Proteomics. 2002;1(3):232-42.

29. Salamone PR, Kavakli IH, Slattery CJ, Okita TW. Directed molecular evolution of ADP-glucose pyrophosphorylase. Proc Natl Acad Sci USA. 2002;99(2):1070-5.

30. Preiss J, Greenberg E, Sabraw A. Biosynthesis of Bacterial Glycogen - Kinetic Studies of a Glucose-1-Phosphate Adenylyltransferase (Ec 2.7.7.27) from a Glycogen-Deficient Mutant of Escherichia-Coli-B. J Biol Chem. 1975;250(19):7631-8

31. Nakamura T, Vrinten P, Hayakawa K, Ikeda J. Characterization of a granule-bound starch synthase isoform found in the pericarp of wheat. Plant Physiol. 1998;118(2):451-9.

32. Ward RM, Gao Q, de Bruyn H, Gilbert RG, Fitzgerald MA. Improved methods for the structural analysis of the amylose-rich fraction from rice flour. Biomacromolecules. 2006;7:866-76.

33. Morell MK, Samuel MS, O'Shea MG. Analysis of starch structure using fluorophore-assisted carbohydrate electrophoresis. Electrophoresis. 1998;19(15):2603-11.

34. Bernfeld P. Amylases, alpha and beta. Method Enzymol. 1955;1:149-58.

35. Regina A, Kosar-Hashemi B, Ling S, Li ZY, Rahman S, Morell M. Control of starch branching in barley defined through differential RNAi suppression of starch branching enzyme Ila and IIb. J Exp Bot. 2010;61(5):1469-82.

36. Miles AA, Misra SS, Irwin JO. The estimation of the bactericidal power of the blood. J Hyg-Cambridge. 1938;38(6):732-49.

37. Hedges AJ. Estimating the precision of serial dilutions and viable bacterial counts. Int J Food Microbiol. 2002;76(3):207-14.

38. Walsh RL, Camilli A. Streptococcus pneumoniae Is Desiccation Tolerant and Infectious upon Rehydration. Mbio. 2011;2(3):e00092-00011.

39. Merritt JH, Kadouri DE, O'Toole GA. Growing and analyzing static biofilms. Curr Protoc Microbiol 2005, Chapter 1:Unit 1B 1.

40. Narisawa N, Furukawa S, Ogihara H, Yamasaki M. Estimation of the biofilm formation of Escherichia coli K-12 by the cell number. J Biosci Bioeng. 2005;99(1):78-80.
41. Burton E, Yakandawala N, LoVetri K, Madhyastha MS. A microplate spectrofluorometric assay for bacterial biofilms. J Ind Microbiol Biotechnol. 2007;34(1):1-4.

42. Montero M, Almagro G, Eydallin G, Viale AM, Munoz FJ, Bahaji A, et al. Escherichia coli glycogen genes are organized in a single glgBXCAP transcriptional unit possessing an alternative suboperonic promoter within glgC that directs glgAP expression. Biochem J. 2011;433:107-17.

43. Homerova DBO, Kofroriov O, Reiuchova B, Kormanec J. Disruption of a glycogen-branching enzyme gene, glgB, specifically affects the sporulation associated phase of glycogen accumulation in Streptomyces aureofaciens. Microbiology. 1996;142:1201-8.

44. Butardo VM, Fitzgerald MA, Bird AR, Gidley MJ, Flanagan BM, Larroque O, et al. Impact of down-regulation of starch branching enzyme Ilb in rice by artificial microRNA- and hairpin RNA-mediated RNA silencing. J Exp Bot. 2011;62(14):4927-41.

45. Elbein AD, Pan YT, Pastuszak I, Carroll D. New insights on trehalose: a multifunctional molecule. Glycobiology. 2003;13(4):17R-27R.

46. Fales FW. The linear relationship between iodine staining and average chain-length of the unbranched amyloglucans. Biopolymers. 1980;19(8):1535-42.

47. Hong SMR, Preiss J. Analysis of the amino terminus of maize branching enzyme $\|$ by polymerase chain reaction random mutagenesis. Arch Biochem Biophys. 2001;386(1):62-8.

48. Pal K, Kumar S, Sharma S, Garg SK, Alam MS, Xu HE, et al. Crystal structure of full-length Mycobacterium tuberculosis H37Rv glycogen branching enzyme: insights of $\mathrm{N}$-terminal beta-sandwich in substrate specificity and enzymatic activity. J Biol Chem. 2010;285(27):20897-903.

49. Zhou K ZR, Stephanopoulos G, Too HP. Enhancing solubility of deoxyxylulose phosphate pathway enzymes for microbial isoprenoid production. Microb Cell Factories 2012, 11.

50. UniProt Consortium. Reorganizing the protein space at the Universal Protein Resource (UniProt). Nucleic Acids Research. 2012;40(D1):D71-5.

51. Lo Leggio L, Ernst HA, Hilden I, Larsen S. A structural model for the N-terminal N1 module of E-coli glycogen branching enzyme. Biologia. 2002;57:109-18.

52. Finn RD, Mistry J, Tate J, Coggill P, Heger A, Pollington JE, et al. The Pfam protein families database. Nucleic Acids Res. 2010;38(Database issue):D211-222.

53. Abad MC, Binderup K, Rios-Steiner J, Arni RK, Preiss J, Geiger JH. The X-ray crystallographic structure of Escherichia coli branching enzyme. J Biol Chem. 2002;277(44):42164-70

54. Seibold GM, Breitinger KJ, Kempkes R, Both L, Kramer M, Dempf S, et al. The glgB-encoded glycogen branching enzyme is essential for glycogen accumulation in Corynebacterium glutamicum. Microbiol-Sgm. 2011;157:3243-51

55. Montero M, Eydallin G, Viale AM, Almagro G, Munoz FJ, Rahimpour M, et al. Escherichia coli glycogen metabolism is controlled by the PhoP-PhoQ regulatory system at submillimolar environmental Mg2+ concentrations, and is highly interconnected with a wide variety of cellular processes. Biochem J. 2009;424:129-41.

56. Folk DGHC, Bradley TJ. Water acquisition and partitioning in Drosophila melanogaster: effects of selection for desiccation-resistance. J Exp Biol. 2001;204:3323-31.

57. Conover MS, Mishra M, Deora R. Extracellular DNA is essential for maintaining Bordetella biofilm integrity on abiotic surfaces and in the upper respiratory tract of mice. Plos One. 2011;6(2):e16861.

58. Jackson DW, Suzuki K, Oakford L, Simecka JW, Hart ME, Romeo T. Biofilm formation and dispersal under the influence of the global regulator CsrA of Escherichia coli. J Bacteriol. 2002;184(1):290-301.

59. Jackson DW, Simecka JW, Romeo T. Catabolite repression of Escherichia coli biofilm formation. J Bacteriol. 2002;184(12):3406-10. 